\title{
Evaluation of Effect of Potassium Solubilizing Microbial Strains on Brinjal
}

\author{
P.P. Nihala Jabin* and Syed Ismail \\ Department of Soil Science and Agricultural Chemistry, Vasantrao Naik Marathwada \\ Agricultural University, Parbhani 431 402, Maharashtra, India \\ *Corresponding author
}

\begin{abstract}
A B S T R A C T
\section{Keywords}

Microbial isolates,

Clearing zone,

Potassium

solubilization, Brinjal,

growth attributes,

Root characters,

Potassium uptake.

Article Info

Accepted:

04 September 2017

Available Online:

10 November 2017

Pot culture experiment was conducted to evaluate the effect of some promising microbial isolates for their ability for potash solubilization in soil as well as to see their effects on growth and yield attributes in brinjal. The laboratory stock cultures [KSB-W1 (Bacillus $s p$ ) KSB-PD-3-A (Bacillus sp), KSB-NP-3 (Bacillus sp), KSB-PD-1-A (Pseudomonas sp), KSB-M-1 (Pseudomonas sp), KSB-M-2 (Pseudomonas sp), KSB-PD (Sinorhizobium metallidans), KSB-PD-1-B (Sinorhizobium metallidans), KSB-M-3 (Sinorhizobium metallidans)] from All India Network Project on Soil Biodiversity-Biofertilizers, VNMKV Parbhani and SKUAST, Kashmir were selected on the basis of their potash solubilizing ability in laboratory condition and used for pot culture. The results immerged out indicated that inoculation of potassium solubilizing microbial isolates considerably enhanced the growth parameters and potassium in brinjal when compared to uninoculated control. Change in plant height and number of leaves was produced significantly highest when inoculation was done with Pseudomonas sp (KSB-PD-1-A), which was found to be at par with the bacterial strain Pseudomonas sp (KSB-M-1) and Pseudomonas sp (KSB-M-2). The highest improvement in root and shoot dry weight and potassium was noted in Pseudomonas sp (KSB-PD-1-A) and Pseudomonas sp (KSB-M-1) treated pots.
\end{abstract}

\section{Introduction}

The potassium is made available to plants when the minerals are slowly weathered or solubilized (Bertsch et al., 1985). In general, black soils are high, red soils medium and lateritic soils less in available K. Lateritic, shallow red and black soils have been found to show decline in $\mathrm{K}$ fertility over the years under intensive cultivation and imbalanced fertilizer application. Soil microorganisms are supportive in the transformation of soil potassium $(\mathrm{K})$ and are thus an important component of the soil $\mathrm{K}$ cycle. Major amounts of $\mathrm{K}$ containing minerals (muscovite, orthoclase, biotite, feldspar, illite, mica) are present in the soil as a fixed form which is not directly taken up by the plant (Bahadur et al., 2014). The needs of $K$ in plants are usually obtained through fertilizer application. However, such effort became inefficient because $\mathrm{K}$ is easily leached by water in the soil in high rainfall zones and get fixed in soil in clayey soils, so that $\mathrm{K}$ becomes unavailable for plants. The inefficiency of $\mathrm{P}$ and $\mathrm{K}$ fertilizer can be solved by using Phosphate Solubilizing Bacteria (PSB) and Potassium Solubilizing Bacteria (KSB), as biological fertilizer. Earlier in this century, scientists found that different bacterial species like 
silicate bacteria were found to dissolve potassium, silicates and aluminium from insoluble minerals (Aleksandrov et al., 1967). Organic matter after decomposition produces acids like citiric acid, formic acid, malic acid, oxalic acid. These organic acids produced, enhance the dissolution of potassium compounds by supplying protons and by complexing $\mathrm{Ca}^{2+}$ ions. Solubilization of potassium occurs by complex formation between organic acids and metal ions such as $\mathrm{Fe}^{2+}, \mathrm{Al}^{3+}$ and $\mathrm{Ca}^{2+}$ (Styriakova et al., 2003). Microbial inoculants that are able to dissolve potassium from mineral and rocks have influence on plant growth and have both economic and environmental advantage. Using K-solubilizing microbes to increase the concentration of available $\mathrm{K}$ ions in the soil may mitigate $\mathrm{K}$ deficiency (Barker et al., 1998).

Thus, by knowing the importance of these microorganisms in plant growth promotion and nutrient solubilization according to literature, we select the nine species of microbial strains such as cultures [KSB-W1 (Bacillus sp) KSB-PD-3-A, (Bacillus sp), KSB-NP-3 (Bacillus sp), KSB-PD-1-A (Pseudomonas sp), KSB-M-1 (Pseudomonas $s p$ ), KSB-M-2 (Pseudomonas sp), KSB-PD (Sinorhizobium metallidans), KSB-PD-1-B (Sinorhizobium metallidans), KSB-M-3 (Sinorhizobium metallidans)].

These strains were tested for plant growth promotion in brinjal under pot culture assay. Microbial inoculants that are able to dissolve potassium from minerals and rocks have influence on plant growth and have both economic and environmental advantage. Thus, keeping this in the view present study was undertaken for "Assessing solubilization potential of insoluble potassium source by using potassium solubilizing microorganisms in plate as well as broth assay. Further, these $\mathrm{K}$ solubilizing microorganisms were tested for growth promotion and $\mathrm{K}$ uptake under pot culture experiment.

\section{Materials and Methods}

The laboratory stock cultures [KSB-W1 (Bacillus $\quad s p$ ) KSB-PD-3-A, (Bacillus $s p$ ),KSB-NP-3 (Bacillus sp), KSB-PD-1-A (Pseudomonas sp), KSB-M-1 (Pseudomonas $s p$ ), KSB-M-2 (Pseudomonas sp), KSB-PD (Sinorhizobium metallidans), KSB-PD-1-B (Sinorhizobium metallidans), KSB-M-3 (Sinorhizobium metallidans)] from All India Network Project on Soil BiodiversityBiofertilizers, VNMKV Parbhani and SKUAST, Kashmir were selected on the basis of their potash solubilizing ability in laboratory condition.

One pot culture soil experiment carried out to study Potassium solubilization potential of different microorganisms using brinjal as a test crop. For this purpose potassium deficient soil used in pot culture experiment. The soil was air dried, sieved and sterilized at $121^{\circ} \mathrm{C}$ for 1 hour for 3 consecutive days and filled in the pots of $6 \mathrm{~kg}$ holding capacity. The experiment was conducted at space behind UG Laboratory, Department of Soil Science and Agricultural Chemistry, Vasantrao Naik Marathwada Krishi Vidyapeeth, Parbhani during 2016-17. Tenth day after sowing 24hrs old fresh microbial isolates [KSB-W1 (Bacillus sp) KSB-PD-3-A, (Bacillus $s p$ ), KSB-NP-3 (Bacillus sp), KSB-PD-1-A (Pseudomonas sp), KSB-M-1 (Pseudomonas $s p$ ), KSB-M-2 (Pseudomonas sp), KSB-PD (Sinorhizobium metallidans), KSB-PD-1-B (Sinorhizobium metallidans), KSB-M-3 (Sinorhizobium metallidans)] inoculated at 10 $\mathrm{ml}$ per pot as per the treatment. The experiment was laid out in a completely randomized design (CRD) with three replications. The growth parameters like plant height and number of leaves were recorded at 90 and 150 days after sowing. $\mathrm{K}$ content in 
plant was determined as per procedure given by Jackson (1973) and uptake was calculated.

\section{Statistical analysis}

The data obtained from the laboratory experiment as well as pot culture was done by completely randomized design as per the methods described in "Statistical Methods for Agricultural Workers" by Panse and Sukhatme (1985).

Appropriate standard error (S.E.) and critical differences (C.D.) at 5\% level were worked out as and when necessary and used for data interpretation.

\section{Results and Discussion}

\section{Plant growth characters}

The inoculation of bacteria solubilizing potassium had significant influence on different plant growth characters. Based on the efficiency of $\mathrm{K}$ solubilization, the nine selected bacterial isolates were further examined for their performance to enhance Growth characters such as plant height and number of leaves over control.

Plant height was measured at flowering (90 DAT) and harvesting (150 DAT) stage of crop growth and data presented in Table 1 . The highest value for plant height and number of leaves were noticed in inoculation with Pseudomonas sp (KSB-PD-1-A) i.e., 28.50 and $30.66 \mathrm{~cm}$ and 29.67 and 27 respectively.

\section{Shoot and root characters}

The oven dry weight of shoot and root varied from 6.73 to $3.23 \mathrm{~g}$ and 0.51 to $0.33 \mathrm{~g}$. Microbial strain Pseudomonas sp (KSB-PD1-A) produced significantly highest oven dry weight of shoot and root (6.73 and $0.51 \mathrm{~g}$ ) followed by Pseudomonas sp (KSB-M-1)
(6.46 and $0.50 \mathrm{~g}$ ) and Pseudomonas sp (KSBM-2) (6.1 and $0.50 \mathrm{~g}$ ). Whereas, lowest dry weight of shoot and root was noticed in uninoculated control (3.23 and $0.33 \mathrm{~g}$ ) (Figs. 1 and 2).

\section{Potassium content and uptake}

Significant differences were observed with K content and uptake in brinjal plant with inoculation of different $\mathrm{K}$ solubilizing microorganisms and the data is presented in Table 2. $\mathrm{K}$ content and uptake in brinjal plant varied from $1.567-2.367 \%$ and $0.051-0.159 \mathrm{~g}$ pot $^{-1}$. Results revealed that the significantly highest $\mathrm{K}$ content and uptake was noted with the microbial strains Pseudomonas sp (KSBPD-1-A) (2.367\% and $\left.0.159 \mathrm{~g} \mathrm{pot}^{-1}\right)$, followed by Pseudomonas sp (KSB-M-1) (2.233\% and $0.144 \mathrm{~g} \mathrm{pot}^{-1}$ ) and superior over other treatments.

Work done by Prajapati (2015) indicated the largest increase in plant height in soil inoculated with $\mathrm{KSB}$ strain compared to the uninoculated soil. Our results are also concur with the findings of Zhang and Kong (2014) who reported that seedlings inoculated with KSB showed greater height than uninoculated seedlings.

Our results are also corroborating with the findings of earlier workers. Chishi, (2010) found that inoculation of KSB showed higher number of leaves as compared with control. Basavesha (2013) also found that the inoculation of potassium solubilizing bacteria increased the number of leaves in plant significantly superior over control. It may be due to inoculation of KSB strains which can synergistically solubilized Rock $\mathrm{K}$ that were added into soil and make them much more available for uptake by plant root and leading to plant growth (Sheng, 2005). The decrease in number of leaves at later stage might be a result of senescence. 
Table.1 Effect of different potassium solubilizing microbial inoculants on plant height and number of leaves

\begin{tabular}{|c|c|c|c|c|}
\hline \multirow{2}{*}{ Treatment } & \multicolumn{2}{|c|}{ Plant height $(\mathbf{c m})$} & \multicolumn{2}{|c|}{ Number of leaves } \\
\hline & $90 \mathrm{DAT}^{*}$ & $150 \mathrm{DAT}$ & $90 \mathrm{DAT}$ & $150 \mathrm{DAT}$ \\
\hline $\mathbf{T}_{1}$ : Uninoculated control & 19.50 & 20.50 & 15.33 & 13.67 \\
\hline $\mathbf{T}_{2}: \mathrm{RDF}+$ Bacillus sp (KSB-W1) & 20.66 & 22.80 & 21.00 & 18.67 \\
\hline $\mathbf{T}_{\mathbf{3}}: \mathrm{RDF}+$ Bacillus sp (KSB-PD-3-A) & 25.03 & 27.16 & 24.33 & 23.00 \\
\hline $\mathbf{T}_{4}:$ RDF + Bacillus sp (KSB-NP-3) & 22.00 & 23.16 & 21.33 & 19.33 \\
\hline $\mathbf{T}_{5}: \mathrm{RDF}+$ Pseudomonas sp (KSB-PD-1-A) & 28.50 & 30.66 & 29.67 & 27.00 \\
\hline $\mathbf{T}_{6}: \mathrm{RDF}+$ Pseudomonas sp (KSB-M-1) & 27.50 & 29.00 & 27.67 & 24.67 \\
\hline $\mathbf{T}_{\mathbf{7}}: \mathrm{RDF}+$ Pseudomonas sp (KSB-M-2) & 26.63 & 28.33 & 26.00 & 23.67 \\
\hline $\mathbf{T}_{\mathbf{8}}: \mathrm{RDF}+$ Sinorhizobium metallidans (KSB-PD) & 24.16 & 26.56 & 23.00 & 20.33 \\
\hline $\mathbf{T}_{\mathbf{9}}:$ RDF + Sinorhizobium metallidans (KSB-1-B) & 24.73 & 26.93 & 23.67 & 22.00 \\
\hline $\mathbf{T}_{\mathbf{1 0}}:$ RDF + Sinorhizobium metallidans (KSB-M-3) & 23.66 & 25.66 & 23 & 19.67 \\
\hline GM & 24.24 & 26.08 & 23.5 & 21.20 \\
\hline $\mathrm{SE} \pm$ & 0.84 & 1.01 & 1.12 & 1.06 \\
\hline $\mathrm{CD}$ at $5 \%$ & 2.55 & 3.13 & 3.41 & 3.23 \\
\hline $\mathrm{CV} \%$ & 6.91 & 7.71 & 9.51 & 10.04 \\
\hline
\end{tabular}

*DAT- Days after transplantin

Table.2 Effect of potassium solubilizing microbial inoculants on potassium content and uptake in brinjal

\begin{tabular}{|l|c|c|}
\hline Treatments & K content $(\%)$ & K uptake $\left(\mathrm{g} \mathrm{pot}^{-1}\right)$ \\
\hline $\mathbf{T}_{\mathbf{1}}:$ Uninoculated control & 1.567 & 0.051 \\
\hline $\mathbf{T}_{\mathbf{2}}: \mathrm{RDF}+$ Bacillus sp (KSB-W1) & 1.633 & 0.057 \\
\hline $\mathbf{T}_{\mathbf{3}}: \mathrm{RDF}+$ Bacillus sp (KSB-PD-3-A) & 2.217 & 0.126 \\
\hline $\mathbf{T}_{\mathbf{4}}: \mathrm{RDF}+$ Bacillus sp (KSB-NP-3) & 1.767 & 0.066 \\
\hline $\mathbf{T}_{\mathbf{5}}: \mathrm{RDF}+$ Pseudomonas sp (KSB-PD-1-A) & 2.367 & 0.159 \\
\hline $\mathbf{T}_{\mathbf{6}}: \mathrm{RDF}+$ Pseudomonas sp(KSB-M-1) & 2.233 & 0.144 \\
\hline $\mathbf{T}_{\mathbf{7}}: \mathrm{RDF}+$ Pseudomonas sp (KSB-M-2) & 2.200 & 0.133 \\
\hline $\mathbf{T}_{\mathbf{8}}: \mathrm{RDF}+$ Sinorhizobium metallidans (KSB-PD) & 1.967 & 0.083 \\
\hline $\mathbf{T}_{\mathbf{9}}: \mathrm{RDF}+$ Sinorhizobium metallidans (KSB-1-B) & 2.067 & 0.099 \\
\hline $\mathbf{T}_{\mathbf{1 0}}: \mathrm{RDF}+$ Sinorhizobium metallidans (KSB-M-3) & 1.800 & 0.067 \\
\hline GM & 1.982 & 0.099 \\
\hline SE \pm & 0.038 & 0.003 \\
\hline CD at 5\% & 0.131 & 0.012 \\
\hline CV \% & 3.881 & 7.088 \\
\hline
\end{tabular}


Fig.1 Root dry weight influenced by different potassium solubilizing microbial inoculants

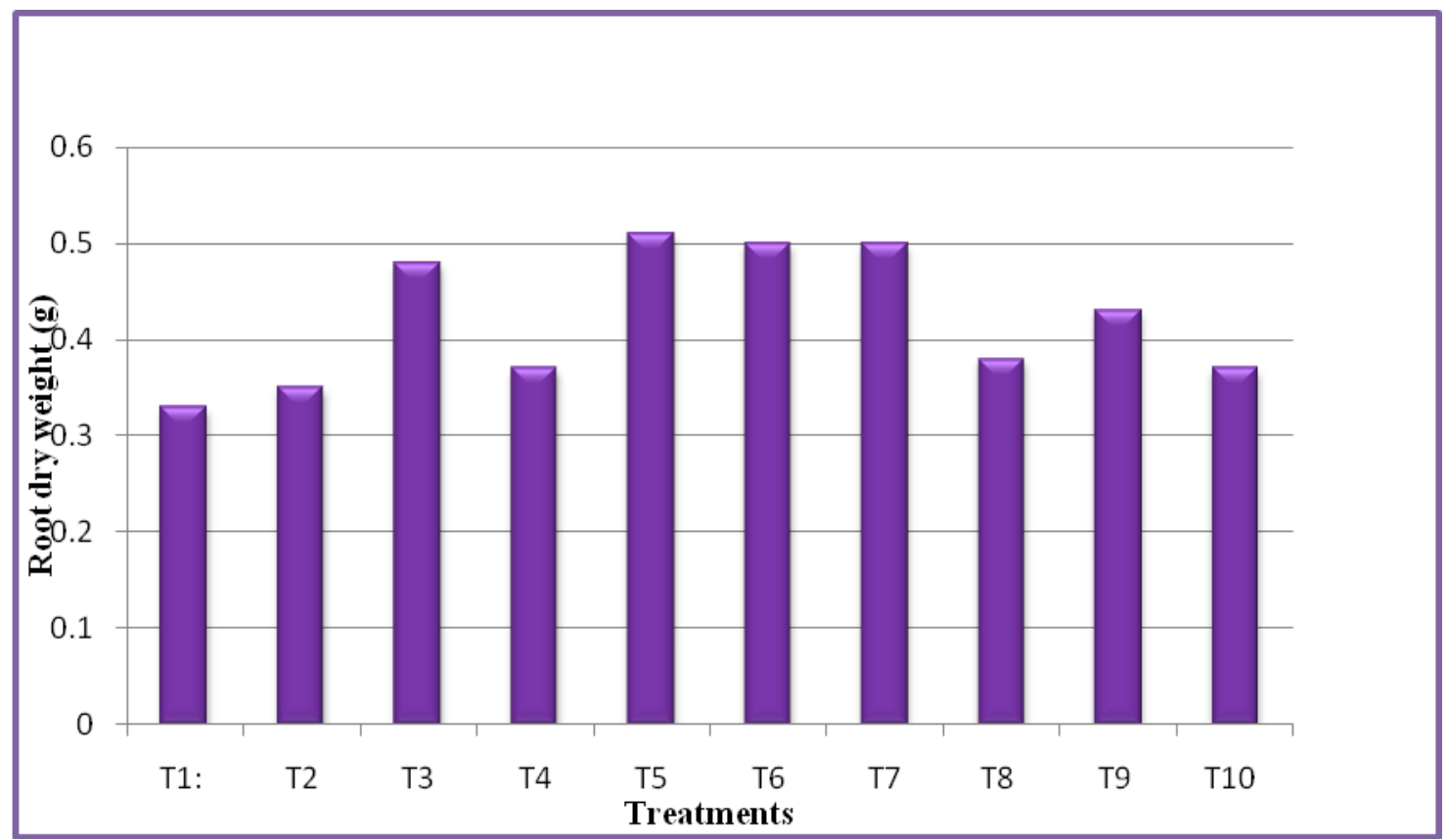

Fig.2 Shoot dry weight influenced by different potassium solubilizing microbial inoculants

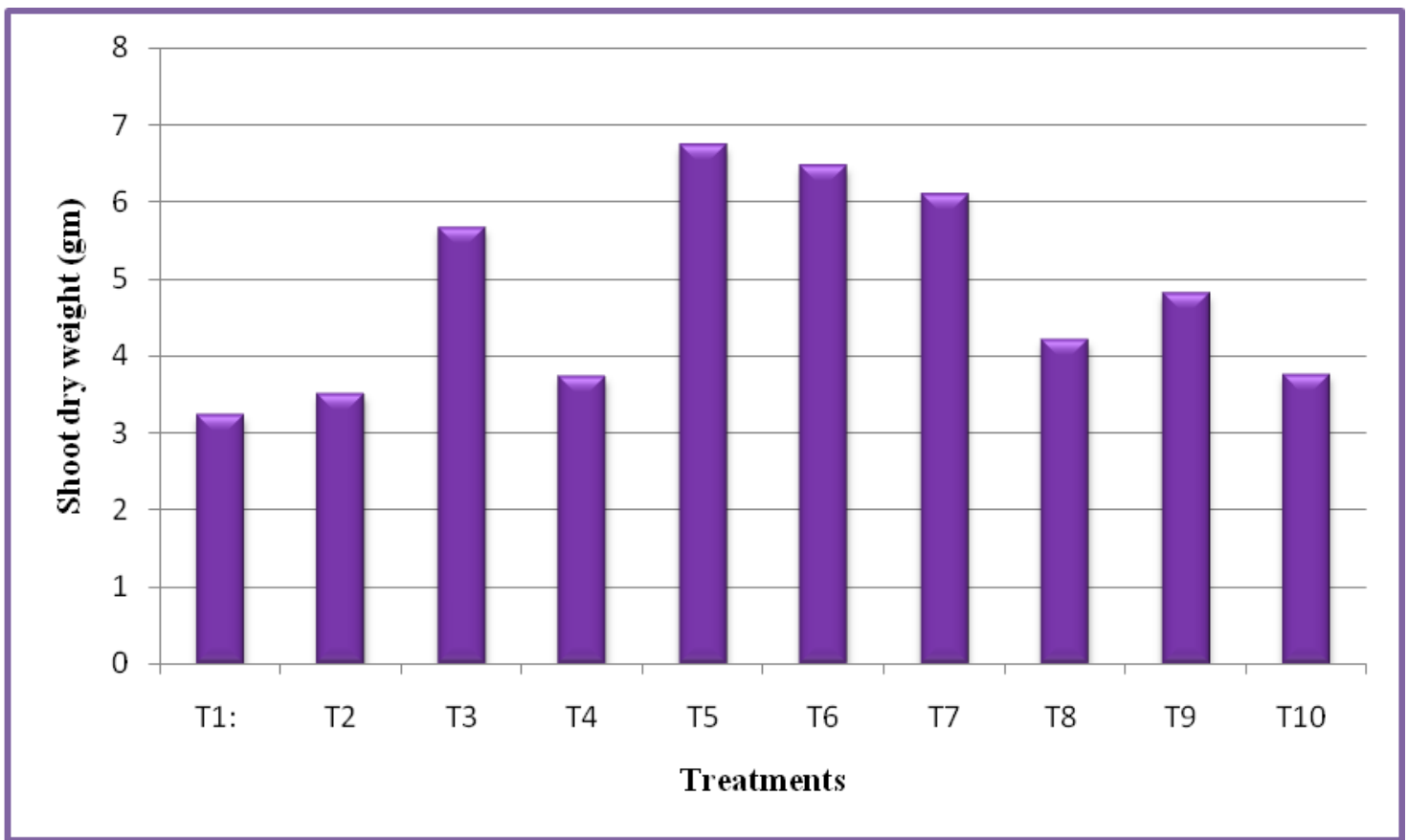

All the treatments receiving inoculation of KSB increased the dry weight of shoot and root of brinjal plant over control. These results were in agreement with the findings of Basak and Biswas (2009) who noticed that inoculated treatment recorded $36.6 \%$ higher biomass yield over uninoculated treatment. Similar results were also reported by Prajapati (2015) who reported that soil inoculation with KSB and KSF significantly increased plant 
growth in terms of shoot and root length, shoot and root weight, plant height over control. Inoculation of bacterial strains, particularly B. mucilaginosus had enhanced biomass yield either directly by solubilizing soil $\mathrm{K}$ reserve because of its ability to convert $\mathrm{K}$ from unavailable to available form through biological processes or indirectly by stimulating plant growth due to its promoting activities (Basak and Biswas, 2010).

Increased nutrient uptake by plants inoculated with different potassium solubilizing microbial inoculants has been attributed to the production of plant growth regulators at the root interface, which stimulated root development and resulted in better absorption of water and nutrients from the soil. Our results confirmed with the findings of Archana (2007) who reported that maize plants receiving KSB inoculation showed significantly higher $\mathrm{K}$ uptake over the control. This release (organic acids, IAA, GA) was reflected in the higher uptake of $\mathrm{K}$ by plants.

In pot culture the microbial strains namely, Pseudomonas $s p$ (KSB-PD-1-A) and Pseudomonas sp (KSB-M-1) enhanced growth characters such as plant height, number of leaves, dry weight of shoot and root and the potassium content and uptake by brinjal crop.

\section{Acknowledgement}

We feel grateful to Dr.Z.A.Baba, Incharge of Microbiology and Biofertilizer Unit, SKUAST, Kashmir for providing the microbial strains for this study

\section{References}

Aleksandrov, V. G., Blagodyr, R.N and Live, I.P. (1967). Liberation of phosphoric acid from apatite by silicate bacteria. Microchem. J. 29: 111-114.
Archana, D.S. (2007). Studies on potash solubilizing bacteria. Ph.D theses. Dept of agricultural microbiology, UAS Dharwad. India.

Bahadur, I., Kumar, S and Meena, V.S. (2014). Importance and application of potassic biofertilizer in Indian agriculture. Int. Res. J. Biological Sci. 3(12): 2278-3202.

Barker, W.W., Welch, S.A., Chu, S and Banfield, J.F. (1998). Experimental observations of the effects of bacteria on aluminosilicate weathering. Am.Mineral.83:1551- 1563.

Basak, B and Biswas, D.R. (2009). Influence of potassium solubilizing microorganism Bacillus mucilaginosus and waste mica on potassium uptake dynamics by sudan grass. Sorghum vulgare Pers. grown under two Alfisols. Plant Soil. 317: 235-255.

Basak, B and Biswas, D.R. (2010). Coinoculation of potassium solubilizing and nitrogen fixing bacteria on solubilization of waste mica and their effect on growth promotion and nutrient acquisition by a forage crop. Biol Fertil. Soils. 46: 641-648.

Basavesha, K.N. (2013). Studies on bacteria solubilizing both potassium and phosphorus and their effect on maize (Zea mays). M.Sc. (Agri.) Theses. College of Agriculture, Dharwad. India.

Bertsch, P.M and Thomas, G.W. (1985). "Potassium status of temperature region soils." In: Munson, R. D. (Ed.) Potassium in agriculture ASA, CSSA and SSSP, Madison, WI, pp.131-162.

Chishi, K.Y (2010). Studies on dual inoculation of potassium solubilizing bacteria and phosphorus solubilizing bacteria on growth and yield of maize (Zea mays L.). M.Sc. (Agri.) Theses. Agricultural Microbiology UAS, Dharwad. India.

Jackson, M.L (1973). Soil Chemical Analysis. 
Prentice Hall of India Pvt. Ltd. New Delhi.

Panse, U.G and Sukhatme, P.V (1985). Statistical Methods for Agricultural Workers. I.C.A.R. Pub., New Delhi. India.

Prajapati, K.B (2015). Impact of potassium solubilizing bacteria on growth and yield of mungebean Vigna radiate. Indian J. Appl Res. 6(2): 390-392.

Sheng, X.F (2005). Growth promotion and increased potassium uptake of cotton and rape by a potassium releasing strain of Bacillus edaphicus. Soil Biol. Biochem. 37: 1918-1922.
Sparks, D.L. (1987). Potassium dynamics in soils. Adv. Soil Sci.6:1-63.

Styriakova, I., Styriak, I., Galko, I., Hradil D. and Bezdicka, P (2003). The release of iron-bearing minerals and dissolution of feldspar by heterotrophic bacteria of Bacillus species. Ceramics Silicaty. 47(1):20-26.

Zhang, C and Kong, F (2014). Isolation and identification of potassium solubilizing bacteria from Tobacco rhizopheric soil and their effect on tobacco plants. Applied soil ecology. 82: $18-25$.

\section{How to cite this article:}

Nihala Jabin, P.P. and Syed Ismail. 2017. Evaluation of Effect of Potassium Solubilizing Microbial Strains on Brinjal. Int.J.Curr.Microbiol.App.Sci. 6(11): 34-40. doi: https://doi.org/10.20546/ijcmas.2017.611.004 